\title{
Visual Culture of a City: Emerging Urban Spaces, Out Of Home Advertising and Public Private Partnership in City Of Bengaluru, India.
}

\author{
Ms. Rashmi Niranjan ${ }^{1}$, Dr. Choodamani Nandagopal ${ }^{2}$ \\ ${ }^{I}$ PhD.Research Student Scholar, Jain University, Bangalore \\ ${ }^{2}$ Dean Department of Humanities, Social Science and Cultural Studies, Jain University, Knowledge Campus, \\ Jayanagar, Bangalore
}

\begin{abstract}
This research paper explores the ways in which the gap between out of home advertising and the public private partnership can be bridged to overcome the difficulties to build the visual culture of modern emerging cities. Bengaluru the Capital of Karnataka is the most happening city of India. The city and its administrative skills been evolving, developing and catalyzing to facilitate and fulfill the needs and expectations of its inhabitants as well as of its increasing population since last two decades. Rapid increase in its population has resulted in extrapolation of many a tangible and intangible element of the city like civic amenities, transportation, tourism, public spaces, entertainment and Out Of Home advertising. This has led the government to turn to private organizations to successfully take part in meeting the challenges of public private $(P P P)$ projects. These tangible and intangible elements come in contact with the moving pedestrians leaving an impression and impact upon the mind of the person of time and space. Being the part of growing economy share of the city and a large chunk of visualscape of city, the new emerging trends of Out Of Home advertising media can be challenging for building the visual culture for the city of Bengaluru. This research paper is in appropriate to and looking forward to possibilities in culminating the visual culture for the city of Bengaluru through Public Private Partnership projects and Out Of Home advertising.
\end{abstract}

Key words: City, Visual Culture, Urban Spaces, Urban Infrastructure, Public Spaces, Out Of Home Advertising, Visual Characters, Public Private Partnership.

JEL Classification: Corporate Social Responsibility

\section{Introduction:}

The cities across the world have changed drastically at unprecedented speed. Each of the cities is identified by their historically marvelous structures or by their technological triumphs. The city of Bengaluru in its hey days of $20^{\text {th }}$ century was known for its greenery, huge parks and lakes for which was appreciated by then Prime Minister Pandit Jawaharalal Nehru, while in $21^{\text {st }}$ century is one of the major centers of the world and known as the silicon valley of India. In the span of almost twenty years beginning from 1985 to 2015, the city of Bengaluru has undergone major changes and trends to keep the pace with the rest of the world. Its natural and salient features, the modern facilities and business opportunities have attracted people within and outside the country. With all new technology and transport facility like Namma Metro, multiscreen theatres, shopping malls, public spaces- the visual imagery of the city has expanded in all directions but in chaos state.

City: The city is a relatively a large and permanent settlement, although there is no any specific agreement on how a city is distinguished from that of a town within general English language meaning, many cities have a particular administrative, legal or historical status based on local law(Kleniewski, 2014). Towns and cities have a long history, although opinions vary on whether any particular ancient settlement can be considered to be a city. Historically in Europe, a city was understood to be an urban settlement with a cathedral. Cities generally have complex systems of sanitation, land usage, housing and transportation (Whitfield, 2005). The concentration of developments greatly facilitates interaction between people and businesses, benefitting both parties in the processes.

The very word city relates to the word 'civility' and 'civilization'. Nature was an environment into which mankind was born, but city is an environment which he has created for himself. It is a place of happenings that both contains and shapes the human life (Whitfield, 2005). It is core of his ideas and energy over the generations that have guided him to build comfortable cities. The past two centuries with the inventions of technology and the present speeding digital technology and nanotechnology has been beneficiary to both man and society largely, at the same time developed troubled relation with growing cities(Friedman, Goetz, 1982), global city (Sassen, 1984), or informational city (Castalls, 1989), and so on. 
In the name of improvement and modernization our cities are losing the green space of the inner city and farmlands of the suburban which have decreased so quickly and overtaken by the asphalted roads and buildings made of concrete and modern materials. Today's cities barren off green spaces and filled with only artificial and non organic materials are having bad effects on the minds of the citizens. The concern for the greenery and the morals of life based with respect to nature and surrounding greenery are vanishing rapidly like that of green spaces of the cities. This kind of attitudes and behaviors will lead the future generation into a very selfishly driven with false ideas about the life in a city. Bengaluru initially known for its lakes, tanks and parks is still a relatively green city compared to other cities of the India but on the verge of losing the remaining green spaces if a right in time action not taken. The department of urban infrastructure in Bangalore should take an initiative to understand the requirement of ideal green spaces within the city along with the venturing upon new urban infrastructure to provide services with a more humanistic approach of visual imagery of the futuristic city of Bengaluru.

Urban Infrastructure: There is no comprehensive study available on history of the urban infrastructure. Through Armstrong et al (1976) one can get to know a bit of important background upon the subject (Hanson 1984). In the past the terms public works and capital infrastructure are interchangeably used to convey the meaning of urban infrastructure. For annotated bibliography of works in the field see, Hoy and Robinson (1982); see also Moehring (1982) and Aldrich (1980). The urban capital infrastructure in U.S.A started around the year 1790. According to Joel.A.Tarr the urban infrastructure is defined as the "sinews" of the city: its transit networks, bridges, roadways; its water and sewer lines and waste disposal facilities; its power systems; its public buildings; and its parks and creation areas. The success of urban infrastructure depends on many elements. They are the demand for public works; the factors affecting their supply; the character of the provider like public, public-private and private type, the relationship of urban infrastructure not only to political, financial, technological, spatial, public health, social and demographic considerations (Hanson,1984) but accounting them as important visual characters which contribute in forming visual culture of the city.

Bird's eye view of the history and evolution of urban infrastructure show how and what trends set in the change and shift in the urban infrastructure. In USA betwen1790-1855 the urban infrastructure laid its foundations. Construction of core infrastructure within the main city was during the period 1855-1910, the automobile revolution from 1910-1956, during the time of rapid urbanization became largely concentrated in the cities of west, while the rural areas were just then influenced. The rise of new extensions of the city and their trends on urban infrastructure was seen during the period of 1956-1982(Hanson, 1984).

At the time that is the early part of twentieth century India was passing through a phase of struggle for the freedom from British rule. During the British administration some of the important infrastructures were undertaken like construction of railways, bridges, dams, roads and hospitals and churches. Any developed area has specific functions to deliver to its user in a city. Each of these areas has ownership and control system to operate its functional use. Hence the city spaces can be categorized into public, semi-public, semi-private and private spaces. To public spaces the access is not restricted for example the roads, sea beaches, gardens and city squares. Access to semi-public spaces is restricted to an identified group of people or members but it is possible for any person from general public can become a member or join the group by completing formalities of giving application and paying fees etc. for example swimming pool, gymkhana, exhibition grounds etc. semi-private spaces are incidental to adjacent private use and where ownership and control of the area vests in some identified group. The access to these semi-private areas is restricted to property holders, owners and visitors. Pathways, side and front open spaces around multistoreyed buildings, roads and gardens in the society are the example of semi-private spaces. Private spaces are under absolute control of an individual or a family where the entry is restricted unless permitted by the property owner (Apte,P.M). Public spaces are the ideal location where most of the urban infrastructure projects are planned as they are designed to serve the public. So these urban infrastructures are the first to be viewed and interacted by the citizen. As it is known factor that the first impression is the lasting impression hence it is essential to build the visual imagery of the city through the use of urban infrastructural spaces which depict the visual culture of the city.

Namma Metro is the mass transit of $21^{\text {st }}$ century city of Bangalore, which literally meaning 'Our Metro' also known as Bangalore Metro is the product of the needs and demands of the time and the citizens (Apte.P M). Namma Metro was initially conceived as a Public Private Partnership project in 1993. The detail project report (DPR) for Phase I of Namma Metro project was prepared by the Delhi Metro Rail Corporation (DMRC) and submitted to BMRCL in 2003. The final approval took many years and the change of government also delayed the commencing of construction of metro. Finally under the BMRCL (Bangalore Metro Rail Corporation Limited) a joint venture of the Government of India and the Government of Karnataka, the first stretch between Baiyyappanhalli and M.G.Road was inaugurated on $20^{\text {th }}$ October 2011 . The second stretch 
between Sampige road and Peenya Industrial area was inaugurated on $1^{\text {st }}$ march $2014 .^{1}$ The introduction of Bangalore Metro has given a scope to further think upon the visual culture of the city at an elevated level.

Visual Culture: Visual culture has existed as a field of study since the 1980's. There have been various ways and means adopted by each one of the many authors to understand the multifaceted meaning of visual culture. The many approaches concentrate around whether the visual culture is defined by its objects, or its subjects or the focus lies within the details of method of approach itself. Many scholars of course tried to incorporate all the elements. (Sparrman, 2004).

To understand the term visual culture let us begin with the first word of the whole that is visual which means anything and everything that comes in contact with our vision or visual field that is perceptible by the sense of sight. For example the pictures, images, photographs and contemporary modes of visual communication media and the last but not the least is the future communication technologies we will encounter in near future. The contemporary world of visual communications is changing significantly as people are learning to interpret communications through visuals better than through text. ${ }^{2}$

Culture on the other hand is the traditions, behaviors and beliefs of the community we belong to or identify ourselves with. When we interact with daily basis especially when we see paintings, sculptures, new technologies rising, different genres of advertisement, new trends in fashion and a lot more, as we look at it every day, we see more than just mere objects, we see our culture. Hence culture is strongly visible in the visual images that we see around us, can be considered as evidences of our culture. As we understand that visual images are reflections of culture thus the term Visual Culture was born.

Visual Culture is mainly about studying through visual images. As most of us will perceive how a culture could have been recorded and could have been a part of history, we would think of the written records first. But, pictures and relics can be more valuable as evidences of existence and other traditions. The twentyfirst century is called as an era of identity, which obviously is visual in nature. According to Nicholas Mirzoeff, Visual Culture is considered a tactic for studying the past until the present functions of the world covered through pictures, images, and other visualizations, rather than through written facts such as texts and words. Visual Culture gives us a better understanding about our culture and probably, our history. It is even more realistic than any other recorded facts which are written down. Visual culture connects art to everyday life. Especially through the images and photographs seen in any of the advertisements in outdoor and indoor advertising media, print media as well as the other media of communications mainly like internet and other technologies. In this paper the term visual culture is used in context to Out Of Home advertising. The $\mathrm{OOH}$ is an emerging trend in contemporary postmodern cityscapes all over the world.

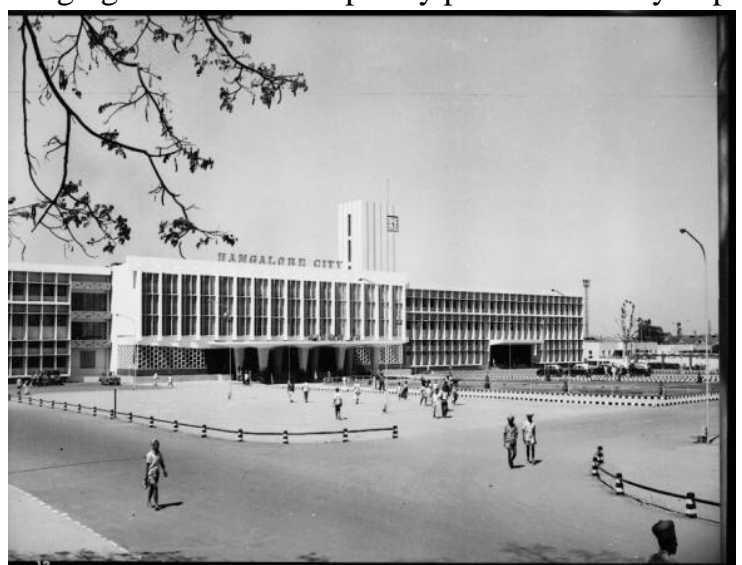

Bangalore Railway Station - year 1975

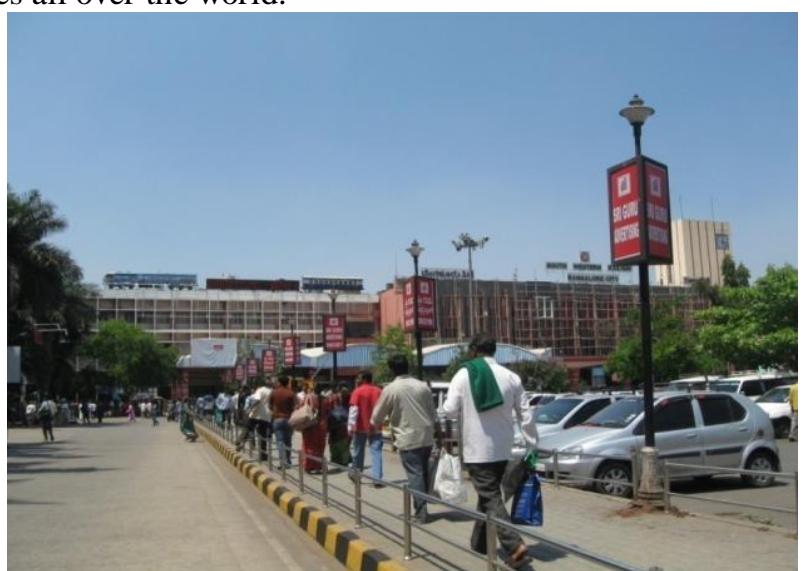

Bangalore Railway Station-year 2010

Out Of Home Advertising: Cities have historically provided spaces for advertising as Bernstein (1997:12) puts it "Advertising Began Outdoors", is very much evident when the street callers and town criers were hired to announce their whereabouts to the potential buyer's convenience in the vegetable and fruit markets held in city squares. The other proofs and forms of outdoor advertising are the commercial messages and political campaign displays found in ruins of Pompeii. Lost and found advertising on papyrus was common in ancient Greece and ancient Rome. When the civilizations grew and new technology invented the outdoor advertising too changed to

\footnotetext{
$1<\underline{\text { http://en.wikipedia.org/wiki/Namma Metro }>}$
}

\footnotetext{
${ }^{2}<$ http://comm265vrvc.blogspot.com/2010/04/rhetoric-of-visual-arguements.html >
} 
many a new forms. Outdoor advertising is essentially any type of advertising that reaches the consumer while he or she is outside the home. This is in contrast with broadcast, print, and internet advertising. Outdoor advertising formats are infinite but majorly be grouped into four main categories: billboards, street furniture, transit, and alternative advertising. While once the outdoor advertising was dominated by the static billboards and shop signs, now outdoor advertisement are seen on moving vehicles which we identify as transit advertising and the street furniture advertisement are found on bus shelters, public toilets and public phones etc, the alternative advertisements are the most creative, engaging and unique in their approach.

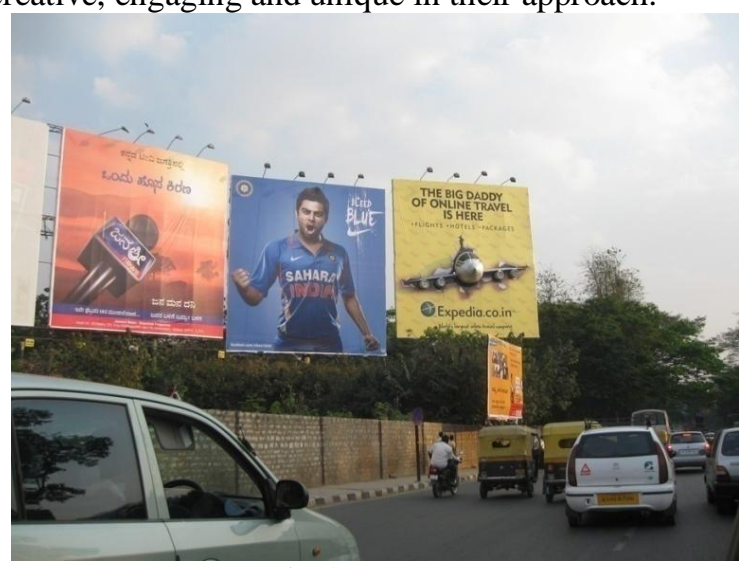

Fig.1. Billboard

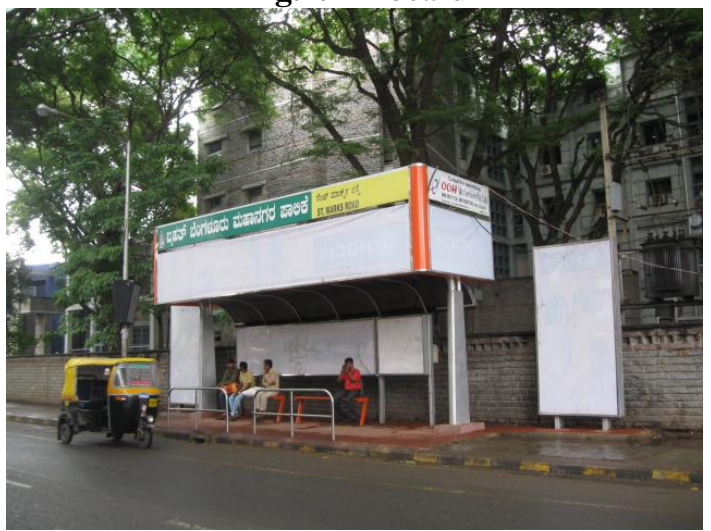

Fig.2.StreetFurniture

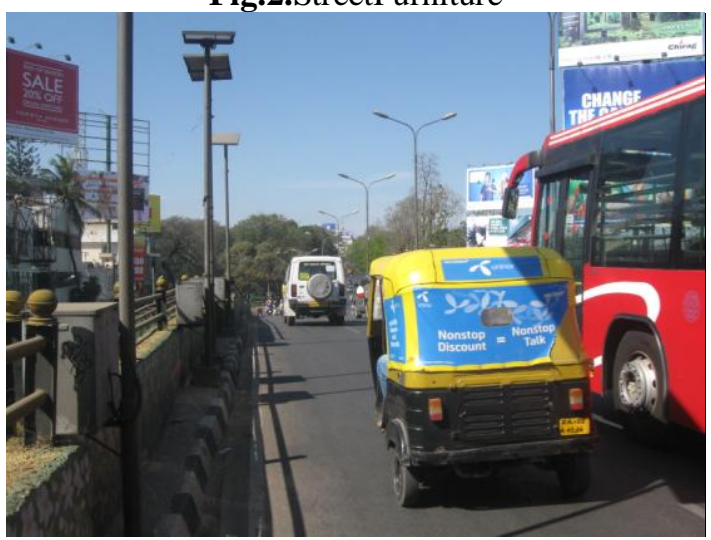

Fig.3.Transit Advertising 


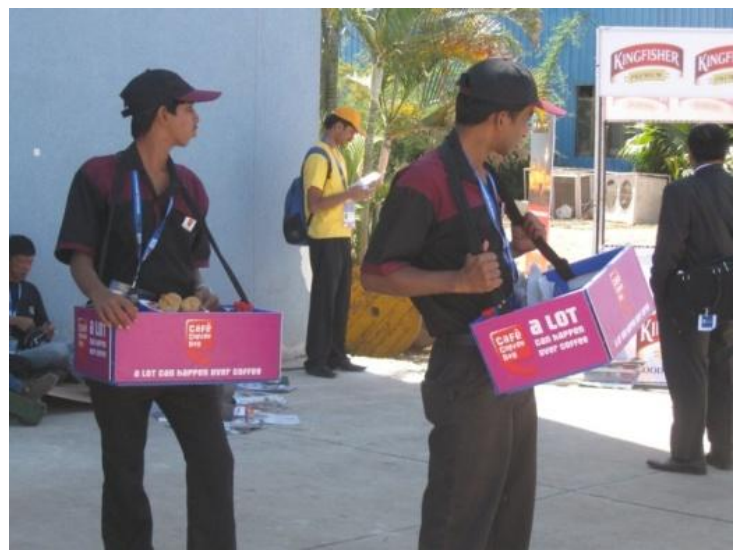

Fig.4.Alternative Advertising

Though Mobile advertising is an emerging, most effective and efficient form of advertising, reaching more number of consumers at a lower Cost per Thousand Impressions (CPM) than any other form of advertising, the out of home advertising is considered more dynamic and engaging as they are big in size that cannot be missed despite heavy traffic and also due to their strategic placing amongst the urban spaces. Due to their unique placing in the spaces of the city the messages they carry in the form of image as well as text is most influencing on the minds of people and hence it is the responsibility of the advertising agency and the public organizations to maintain certain laws of the field and the profession. Mobile advertising is really being mobile in nature as it reaches the stake holder whether is indoor or outdoor, relaxing or at workplace, can be tapped to culminate with out of home advertising that can help in building visual culture of the city.

Emerging Urban Spaces: Today the urban spaces we identify are due to their commercial outburst with cars, transport systems and retail developments (Hamm, 2007). These varied transportation and other systems gave birth to new urban spaces like fuel stations, car parking slots in and around the residential, all kinds of recreational areas like parks, community centers, drama theatres and multiplexes, office spaces, multistoried pay and park structures and so on. Improvement in the existing roads by widening the breadth, introducing underpass and great dividers, more number of signal junctions to serve the increasing vehicles thereby creating volume of outdoor spaces for the out of home advertising. Many of these new urban structures and spaces are result out of public private partnership projects.

Public Private Partnership: Government service or private business venture which is funded and operated through a partnership of government and one or more private sector companies, sometimes referred as PPP or P3. There is varying understanding amongst the stakeholders as of the term PPP. It is called PPP when it is only an investment by private company, while others contend to include all forms of interactions between the public sector and private sector, from consultations or policy dialogue and collaboration, to private provision of assets and services. Before the governments were formed, the futuristic and administrative skills of emperors and kingdoms all over the world looked into the norms of providing the basic amenities and services to the inhabitants of the empire. As the working systems changed, resulting into industrialization and forming of governments. These governments traditionally looked into the furnishing of public services and infrastructure as their exclusive domain of governance. However with increase in population and its pressure of urbanization and other developmental trends, Governments' ability to execute and attend to the public needs through traditional means has become a difficult task. This has made the modern Governments at the global level to turn towards the private sectors to supplement public investments and provide public services through Public Private Partnerships.

Today's scenario of public- private partnership (PPP) is considered a very important public sector activity for the following reasons, - 1) Governments have recognized the crucial role of infrastructure in fostering economic growth and reducing poverty. 2) Because of its 'public good' and 'essential' nature Governments have attempted to ensure availability of basic civic services irrespective of its market conditions. 3) For number of economic, social and political reasons, private sector involvement in these important areas was slow to develop and thus uneven.

Public Private Partnership in Bengaluru is a result of the initiative taken by the Bangalore Agenda Task Force (BATF) which was conceived by the Government of Karnataka in 1999 under the guidance of the then Chief Minister Sri S M Krishna. The BATF team comprised experts in several fields and headed by Sri Nandan Nilekani. One of the trust areas of the BATF was the creation of urban infrastructure in the form of street furniture and other public utilities. The assets created as result of this are as below:

a) Bus Shelters: Earlier, Bus Queue Shelters in Bangalore were put up by the BTS / KSRTC at main Bus Stands only. In other areas the local philanthropists and Public Sector Companies put up some Bus Shelters near their units. Most of these structures comprised simple poles supporting an asbestos roof. The BATF 
wanted to standardize the Bus Shelters and contribute to the aesthetics of the city. In furtherance of this they designed three types of Bus Shelters. Type A was a futuristic looking shelter, Type B was a simple two poled structure meant for small foothpaths and Type $\mathrm{C}$ had a high roof with a monkey top gable.

b) Public Conveniences: Bangalore did not have many Public Conveniences (Public Toilets). The BATF along with the Infosys Foundation set up several Public Conveniences which were run on a pay and use model. Later the external walls of these were used for displaying advertisements and the income generated subsidized the cost of running these Public Conveniences

c) Road Medians: Most roads in Bangalore were poorly lit. The concept of road medians brought about a semblance of order to the existing road dividers in addition to lighting up the area where the pedestrians were likely to cross.

d) Foot Over Bridges / Skywalks: This has been the most successful of the PPP Projects up to date in terms of people using it. It is normally very difficult to cross large roads with heavy traffic. Pedestrians have to wait for a long time, some times as much as half an hour to safely cross the roads. Building these Sky Walks enabled the pedestrians to cross the roads overhead of the traffic quickly and safely. No doubt it involves walking up a flight of stairs almost two storey's tall.

The above mentioned urban infrastructures like public conveniences, road medians, foot over bridges and skywalks play an important role as visual characters within the city spaces. This new urban infrastructure has changed the visualscape of the city of Bengaluru.

\section{Visual Characters}

The word visual has many dimensions of field of study when attached with another word. For example visual environment, visual language, visual scope, visual basic, visual node, visual element etc. The emerging urban spaces transformed with a boost of the new visual characters in city spaces. In this study conducted during the time period from the year 2011 to 2014 covers all kinds of out of home advertising and its related visual elements like shop name board display, direction information, street name posts and the urban infrastructure are considered as visual characters. The tangible features of these visual characters that are used as surfaces for out of home advertising involve the picture, forms, text and words that populate the street and walkways of the city, turning them into the intangible spaces of meaning making, decoding even the remotest highway with a billboard into a location of market promotion and consumption creating new dimensions and relations amongst the consumers. The out of home advertising elements like billboards, street furniture, transit advertising and alternative advertising promulgate the Cities history, economic, cultural and political messages to the flaneur (Benjamin, 1999). The cities across the world though majorly populated and bustling with commercial activity, only handful of cities can truly be observed as with consistent strong image (Lynch, 1960). This argument leads to know how and why the out of home advertising as visual characters can help in to build a visual culture for the city. The change in scenario of city of Bengaluru started with the setting of public sector companies like HAL, BEL, ISRO, BEML, LIC etc. Both the urban built form (architecture), as well the inbuilt form (public spaces) became the breeding ground for the changing trends in visual culture of city of Bengaluru. The above mentioned companies were the first to put up their name boards and advertisements which later came to be identified as Out Of Home advertising or generally known as outdoor advertising.

The ever changing technology, infrastructure of the city, lifestyle, innovations in the outdoor advertising tools and techniques has had definite influence on visual culture of the city of Bengaluru and its people. For Out Of Home advertisers every outdoor space, nook and corner of the road, shop of the city is important as it is most efficient way to reach the audience like the commuter, passerby, and traveler, be it a youth, old generation as well the new generation (Gudies, 2004). The outdoor advertising spaces, building facades and city streets, roads, gantries and the signal junctions, signboards of all kinds contribute towards building, contributing, and understanding of the visual culture of the place.

This research paper is based on mainly qualitative, historical and exploratory research methodology. Under qualitative methodology professionals and owners from the field of out of home advertising agencies, government agencies and organizations were interviewed on aspects of Out Of Home advertising, public private partnership projects. An extensive literature review about the books, articles on visual culture. A comparative study of city of Bengaluru was conducted based on the old and new photographs. Old photographs collected from the sources like Department of Information and Broadcasting, Bengaluru. The new photographs are the source of author. This paper is partial of the original thesis of the author. The other important personalities who support the idea of beautification of Bengaluru through OOH industry are Mr.M.Laxminarayana, Commissioner of BBMP and Mr. Rajiv Raghunath, Editor, Outdoor Asia.

\section{Acknowledgement}

I thank Mr. Vishwanath Nayak, proprietor of Pinnacle Advertising for his helping in providing information on the subject of public private partnership in out of home advertising and about its benefits for the 
futuristic society. I thank Mr. Manmohan Singh Mann, secretary of Outdoor Advertisers Association, Bangalore. I thank Mr. Anup Dayanand Sadhu, Senior Divisional Commercial Manager, for his support on emerging $\mathrm{OOH}$ advertising opportunities through public private partnershiop at Railway station,Bangalore Division, South Western Railway. I thank Mr.N.Krishna, Production department, MCA. Mr. Basavaraj Bidri, Art Director, MCA for current status on Out Of Home advertising. I thank Mr. Shivraj Patil of Tacit Advertising agency for giving abundant information on outdoor advertising.

\section{Conclusion}

Historically the Indian kingdom, towns and cities visual environment was integral to the temples, palaces and forts. The thriving example is the Hampi in the Indian state of Karnataka declared as world heritage site was a well planned city with the temple as the focal point and the markets placed on either side of the street near the temple. In contrast to are the contemporary cities whose focal points are the commercial hubs, malls, commuting points and routes and refreshing centers in the city. The creation of these new urban infrastructures in the modern cities has provided new spaces and surfaces for the use of Out Of Home advertising. These interesting spaces of the urban environment can be tapped to create interactive spaces through out of home advertising for the betterment of the city. The need of the hour is the managerial skills, regulatory bodies and corporate companies which should come together in synchronizing the required inputs to enhance the visual culture of the important emerging spaces of the city with more number of public private partnership projects in future growth of cities.

\section{References:}

[1]. Anna Sparrman, Ph.D., Researcher, Department of Child Studies, Linköping University,

[2]. Hamm, S. (2007). Bangalore Tiger. New York. McGraw Hill Company.

[3]. Schübeler, P. (1996). Participation and Partnership in Urban Infrastructure Management. Washington.D.C.

[4]. Hanson. R. (ED.) (1984). Perspectives on Urban Infrastructure. Washington.D.C. National Academy Press.

[5]. Tarr, J.A. The Evolution of the Urban Infrastructure in the Nineteenth and Twentieth Centuries.

[6]. Apte, P. M. Urban Planning \& Development: an Indian Perspective.

[7]. Gudies, C. (2004) Buyways: Billboards, Automobiles and the American Landscapes.

[8]. Lynch,K. (1960).The Image of the City. Massachussets Institute of Technology and The President and Fellows of Harvard College.

[9]. Kleniewski. (2014). e study guide for: Cities, Change, and conflict: A political economy of Urban Life. $3^{\text {rd }}$ edition. Content Technologies. Inc. Publications and Services.

[10]. Whitfield,P. (2005). Cities of the World: A History in Maps. London.British Library.

[11]. Benjamin,W. (1999). The Arcades Project. USA 